\title{
QUANTITATIVE MODEL FOR DETERMINING INCENTIVE/DISINCENTIVE AMOUNTS THROUGH SCHEDULE SIMULATIONS
}

\author{
Kunhee Choi \\ Texas A\&M University \\ Department of Construction Science \\ 3137 TAMU \\ College Station, TX 77843
}

\author{
Young Hoon Kwak \\ The George Washington University \\ School of Business \\ Department of Decision Sciences \\ Washington, DC 20052
}

\author{
Byunggu Yu \\ University of the District of Columbia \\ Department of Computer Science \& Information Technology \\ 4200 Connecticut Avenue, N.W. \\ Washington, DC 20008
}

\begin{abstract}
One groundbreaking way of expediting any construction is to offer contractors a monetary incentive. To be effective, the incentive amount should be larger than the contractor's additional cost (CAC) for expediting construction time. Yet, estimating the CAC poses a major challenge because contractors are reluctant to disclose their profit information. This study introduces a quantitative model that estimates realistic CACs through schedule simulations on four different resource usage levels. An innovative and reliable tool called Construction Analysis for Pavement Rehabilitation Strategies (CA4PRS) was used for the simulation. Using CA4PRS, a set of contractors' time-cost tradeoff data was created and a linear regression analysis was performed to predict the CAC growth rate and to analyze how this interacts with the agency's specified schedule goal. The robustness of the proposed model was also validated through a case study. This model can assist decision-makers to make better decisions when estimating optimal incentive amounts.
\end{abstract}

\section{INTRODUCTION}

\subsection{Paradigm Change in Highway Infrastructure Construction}

The nation's aging transportation infrastructure in recent years has created an urgent challenge that state transportation agencies must address immediately: how to effectively renew badly deteriorated infrastructure systems while minimizing traffic inconvenience to the traveling public during lane closures for construction. As a partial response to this challenge, the Obama administration's economic stimulus package included specific funding (about $\$ 80$ billion) targeted for extensive transportation infrastructure rehabilitation and rebuilding projects (US News \& World Report 2009). Moreover, 'improving transportation infrastructure' has been identified as one of the fourteen grand challenges for engineering in the 21st century by the National Academy of Engineering (NAE 2009). 


\section{Choi, Kwak and $Y u$}

From 1999 to 2001, approximately 30 percent of the highway construction projects in the United States were undertaken in urban areas (WisDOT 2004). The typical traffic disruptions incurred by these urban highway construction projects cause major inconvenience to the traveling public and commercial enterprises that rely on the roadways.

In responding to this growing challenge, many state highway agencies (SHAs) have changed their focus from development and construction of new facilities to maintenance and renewal of existing facilities (Herbsman et al. 1995). Research has shown that the traveling public and affected businesses show a willingness to pay higher construction costs when they anticipate that shortened construction schedule will mitigate their overall inconvenience (Choi et al. 2009).

\subsection{Incentives/Disincentives for Achieving Early Project Completion}

To carry out transportation infrastructure improvements, State Highway Agencies (SHAs) have to close portions of highways while minimizing the impact of the necessary traffic changes on the traveling public and area businesses during the construction period. These apparently conflicting requirements demonstrate the challenge that SHAs face: innovative contracting strategies that can both reduce construction duration and lessen unfavorable traffic impact to the traveling public and commercial enterprises that rely on these roadways.

One innovative way of reducing construction duration is to offer contractors an early completion incentive bonus that can motivate them to apply their ingenuity to completing projects early (Christiansen 1987, Jaraiedi et al. 1993). Incentive/disincentive (I/D) contracting has become one of agencies' favored alternative strategies for motivating contractors to fulfill the public's expectation that projects will be completed early. Time-based I/D provisions are one of the most widely used strategies for reducing construction time preferred by SHAs and contractors alike because they can establish win-win solutions for both parties (Ibarra et al. 2002). Adopting these I/D provisions can help agencies save on road-user delay costs by cutting construction time, while contractors can increase their profits by receiving an incentive bonus.

\subsection{Schedule Simulations for Building Baseline Schedule Data}

Construction Analysis for Pavement Rehabilitation Strategies (CA4PRS) was developed in 1999 under the Federal Highway Administration (FHWA) pooled research fund with a multistate consortium (California, Minnesota, Texas, and Washington) to help contractors and developers analyze schedules, costs, and work zone traffic impacts (Figure 1). The software has three main functions to estimate schedule, cost, and work zone. CA4PRS's schedule analysis estimates the duration of highway rehabilitation project in terms of total number of closures (Lee and Ibbs 2005). CA4PRS's work zone analysis quantifies the impact of construction work zone closures on the traveling public in terms of road user cost and time spent in queue (Lee et al. 2008).

CA4PRS has been widely used in California and in four other states. Validation studies on several major highway rehabilitation projects in states including California, Washington, and Minnesota proved the scheduling reliability and accuracy of the software (Lee et al. 2008). As a result, there has been nationally growing acceptance of the program, including recent arrangement by FHWA to provide free group licenses for all fifty states.

In this research, CA4PRS generated the baseline schedule data to quantify the level of contractors' additional cost growth for using additional resources. It was assumed that the simulation using CA4PRS would provide reliable baseline schedule data because it was validated by numerous highway renewal projects. It was specifically used to estimate,

- How many closures (days) the project would take; and

- How many closures (days) a contractor can reasonably eliminate under four given resource levels. 


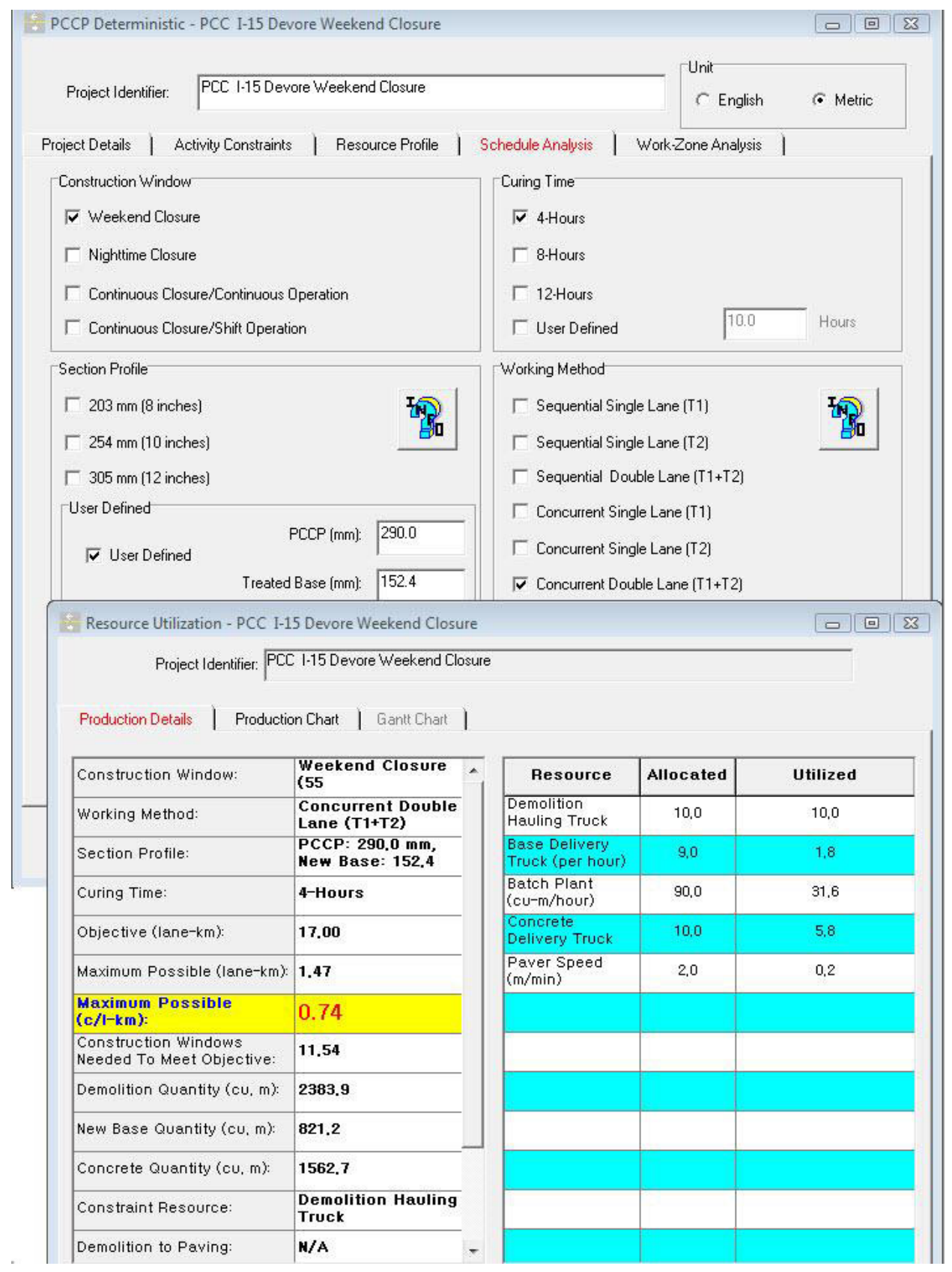

Figure 1: Input and output screen example of the $C A 4 P R S$ schedule simulation

\section{RESEARCH SCOPE AND METHODS}

To properly encourage contractors to complete projects earlier, incentive fees paid should be larger than increases in the contractor's additional costs for expediting construction, which are defined as the lower bound in this study. If the incentive amount is smaller than the contractor's additional cost (CAC), this will not only keep competitive contractors from submitting a bid, it could also create a "winner's curse" for small-scale contractors. In addition, to be economically valid, incentive fees should be less than a por- 


\section{Choi, Kwak and $Y u$}

tion of the decrease in total time savings to road users and the agency, defined as the upper bound in this study. Therefore, incentive fees should satisfy the following relationship:

$$
\mathrm{CAC} \leq \mathrm{I} / \mathrm{D} \leq \text { Discounted total savings to road users and the contracting agency }
$$

A contracting agency that wants to use the I/D contracting method must first determine the monetary value of the time saved by an earlier project delivery. Most SHAs have well-developed methods to establish the I/D upper bound of Equation (1) (Sillars and Riedl 2007). However, estimating the level of contractors' additional cost growth in exchange for shortened construction times is extremely difficult largely because such data is nonexistent. This is due to the fact that contractors are reluctant to disclose data that contains information about their profits, and moreover, it is extremely difficult for a contracting agency to keep track of information about individual contractors' additional cost growth. Even though few researchers reported that they obtained contractors' final construction cost data in an attempt to estimate the level of CAC commitments, the final cost was most likely to be the final cost paid at the end of construction, which includes increases to the original contract bid amount due to contract change orders issued during construction (Shr and Chen 2003).

To overcome the limitation stemming from the absence of methods for establishing the I/D lower bound, this study proposes a new approach to quantify the realistic amount of the lower bound, which can effectively motivate contractors to pursue accelerated construction. Using the schedule simulation function of CA4PRS, a data set of the contractors' time-cost tradeoff was created on four different resource usage levels. CA4PRS was selected for the simulation because its schedule simulation is based on contractors' actual production performance data-the simulation results have been tested and validated on numerous highway rehabilitation projects throughout California. A linear regression analysis was then performed to predict the contractors' additional cost growth rate and its impact on the agency's specified schedule goal.

It is assumed that a contractor will need to use additional resources in an I/D contract if it is planned well to provide sufficient motivation. By this reasoning, four different resource usage levels were considered to quantify the contractors' additional cost growth rates in the following procedures:

1. Identify critical factors affecting rehabilitation production performance;

2. Perform schedule estimates using CA4PRS simulation with four different resource usage levels (Table 1);

3. Determine the unit price ( $\$$ /hour) of all resources used;

4. Calculate contractors' additional costs using Equation (2);

5. Quantify the interaction between contractors' additional cost growth rates and specified schedule compression rates (Table 2);

6. Draw a scatter plot of contractors' additional cost growth rates over schedule compression rates to confirm that the regression data is fit into a quadratic shape;

7. Conduct a linear regression analysis to determine coefficients $\left(\beta_{0}, \beta_{1}\right.$, and $\left.\beta_{2}\right)$;

8. Derive a quadratic equation to reflect contractors additional cost growth as a function of the schedule compression the agency sets;

9. Develop a final quantifying equation by plugging the coefficients into the quadratic equation developed in Step 8; and

10. Conduct a case study to check the robustness of the equation in predicting the actual values of incentive/disincentive amounts.

\section{CONTRACTOR'S SCHEDULE COMPRESSION VERSUS RESOURCES}

Table 1 shows the result of the CA4PRS schedule simulation. Because construction strategies, crosssection design, construction window, and contractor's resource constraints turned out to be four most im- 


\section{Choi, Kwak and $Y u$}

portant factors directly affecting rehabilitation production (Lee and Ibbs 2005), these four factors were taken into account in the schedule simulations using CA4PRS. Each strategy shown in Table 1 is based on actual I/D projects where project scope (lane-miles to be rebuilt) and project size (original contract amount) were similar.

Table 1: CA4PRS Schedule Estimate versus Additional Resource Usage.

\begin{tabular}{|c|c|c|c|c|c|c|c|c|c|c|}
\hline \multirow{3}{*}{ Strategies } & \multirow{3}{*}{$\begin{array}{l}\text { Cross-Section } \\
\text { Profile }\end{array}$} & \multirow{3}{*}{$\begin{array}{l}\text { Construction } \\
\text { Window }\end{array}$} & \multicolumn{8}{|c|}{ Schedule Estimate Versus Additional Resource Usage } \\
\hline & & & \multicolumn{2}{|c|}{ Ordinary Usage } & \multicolumn{2}{|c|}{$5 \%$} & \multicolumn{2}{|c|}{$15 \%$} & \multicolumn{2}{|c|}{$25 \%$} \\
\hline & & & Closures & Days & Closures & $\overline{\text { Days }}$ & Closures & $\overline{\text { Days }}$ & Closures & $\overline{\text { Days }}$ \\
\hline \multirow{6}{*}{ РCCP } & \multirow{3}{*}{8 inches } & Nighttime & 142.00 & 142.00 & 136.00 & 136.00 & 118.00 & 118.00 & 113.00 & 113.00 \\
\hline & & Weekend & 6.88 & 15.76 & 6.55 & 14.99 & 5.98 & 13.69 & 5.50 & 12.59 \\
\hline & & Extended & 3.13 & 25.04 & 2.98 & 23.81 & 2.72 & 21.75 & 2.50 & 20.00 \\
\hline & \multirow{3}{*}{$\begin{array}{l}12 \text { inches with } \\
6 \text { inches ACB }\end{array}$} & Nighttime & 227.14 & 227.14 & 216.32 & 216.32 & 197.51 & 197.51 & 181.71 & 181.71 \\
\hline & & Weekend & 20.06 & 47.17 & 19.41 & 44.91 & 17.91 & 41.01 & 16.48 & 37.74 \\
\hline & & Extended & 6.83 & 54.64 & 6.51 & 52.05 & 5.94 & 47.51 & 5.46 & 43.70 \\
\hline \multirow{3}{*}{ ACP } & \multirow{3}{*}{$\begin{array}{l}6 \text { inches } \\
(3 \times 2 \text { lift })\end{array}$} & Nighttime & 63.32 & 63.32 & 60.30 & 60.30 & 55.06 & 55.06 & 50.66 & 50.66 \\
\hline & & Weekend & 5.65 & 12.94 & 5.39 & 12.34 & 5.09 & 11.66 & 5.08 & 11.63 \\
\hline & & Extended & 1.06 & 7.42 & 1.01 & 7.07 & 0.95 & 6.65 & 0.95 & 6.65 \\
\hline \multirow{3}{*}{ MACO } & \multirow{3}{*}{6 inches } & Nighttime & 126.24 & 126.24 & 120.25 & 120.25 & 109.82 & 109.82 & 101.06 & 101.06 \\
\hline & & Weekend & 17.92 & 41.04 & 17.07 & 39.09 & 15.67 & 35.88 & 14.77 & 33.82 \\
\hline & & Extended & 13.16 & 39.48 & 12.53 & 37.59 & 11.45 & 34.35 & 10.80 & 32.40 \\
\hline
\end{tabular}

The simulation shows that the duration of a project is shortened as the contractor uses more resources. The following shows a brief project overview of each strategy and summarizes all the assumptions made in conducting the schedule estimates.

- Portland Cement Concrete Pavement (PCCP) strategy is based on the Interstate 15 Devore Project where the project scope was to rebuild a 10.7 lane-mile stretch of badly damaged concrete truck lanes (project size: $\$ 18$ million).

- Asphalt Concrete Pavement (ACP) strategy is based on Interstate 710 Long Beach Project where the project scope was to rehabilitate approximately 16.4 lane-mile of a six-lane highway segment (project size: \$16.7 million).

- Milling and Asphalt Concrete Overlay (MACO) strategy is based on Interstate 15 Baker Project where the project scope was to rehabilitate an aging 43.5 lane-mile stretch of two lanes (project size: $\$ 20$ million).

- Construction window and lane closure tactics: A sequential single lane closure with 4-hour curing time was assumed for a nighttime construction window. A concurrent double lane closure with 12-hour curing time was assumed for weekend (55-hour) and extended (24/7) construction windows.

\section{CONTRACTOR'S COST GROWTH VERSUS RESOURCES}

To estimate the cost growth rates of shortening construction duration with more resources, the unit price (hourly rate) information of all the major resources was needed. Such information can be found in publically accessible publications titled Labor Surcharge and Equipment Rental Rates by California Department of Transportation (Caltrans 2008). Caltrans updates the publication annually and revises changes to fuel costs, interest rates, producers' price index, sales tax, and freight rates. The following (hourly) unit prices of major resources were determined based on this publication:

- $\quad$ Truck: $\$ 75.57$ with overtime rate of 0.83

- Paver: $\$ 132.79$ with overtime rate of 0.83

- Milling machine: $\$ 362.59$ with overtime rate of 0.87 


\section{Choi, Kwak and $Y u$}

- Batch plant: $\$ 615$ with over time rate of $0.56(\$ 6.25 /$ tonne $)$.

These four are major resources used by CA4PRS simulations. The unit prices include the labor costs required to provide the above listed items. The labor surcharge compensates the contractor for statutory payroll items including workers' compensation, social security, fringe benefits, federal unemployment, state unemployment, and state training taxes (Caltrans 2008). The published surcharge rates for year 2008 were $12 \%$ for regular time and $11 \%$ for overtime. Multiple shift hours are paid at the same rate as overtime hours. The unit prices, however, do not include the operator costs of equipment due to the lack of such data.

Contractor's expected cost growth $=$ unit price $(\$ /$ hour $) \times$ number of additional resources

$\mathrm{x}$ labor surcharge rate $\mathrm{x}$ working hours per day $\mathrm{x}$ days needed to complete the project

$\mathrm{x}$ overtime rate $\mathrm{x}$ number of shifts $\mathrm{x}$ overhead cost $(15 \%)$

Contractors' additional cost growth rates were quantified based on Equation (2). Table 2 contains the dependent (cost) and independent (schedule) variables used for the regression analysis, with three different resource usage levels.

Table 2: Contractor's Additional Cost Growth on Extra Resource Commitments.

\begin{tabular}{|c|c|c|c|c|c|c|c|c|}
\hline \multirow{3}{*}{ Strategies } & \multirow{3}{*}{$\begin{array}{c}\text { Cross-Section } \\
\text { Profile }\end{array}$} & \multirow{3}{*}{$\begin{array}{l}\text { Construction } \\
\text { Window }\end{array}$} & \multicolumn{6}{|c|}{ Time-Cost Tradeoff versus Additional Resource Usage } \\
\hline & & & \multicolumn{2}{|c|}{$5 \%$} & \multicolumn{2}{|c|}{$15 \%$} & \multicolumn{2}{|c|}{$25 \%$} \\
\hline & & & $\begin{array}{c}\text { Schedule } \\
\text { Compression } \\
\end{array}$ & $\begin{array}{c}\text { Cost } \\
\text { Growth }\end{array}$ & $\begin{array}{c}\text { Schedule } \\
\text { Compression }\end{array}$ & $\begin{array}{c}\text { Cost } \\
\text { Growth }\end{array}$ & $\begin{array}{c}\text { Schedule } \\
\text { Compression }\end{array}$ & $\begin{array}{c}\text { Cost } \\
\text { Growth }\end{array}$ \\
\hline \multirow{6}{*}{ РCCP } & \multirow{3}{*}{8 inches } & Nighttime & 4.23 & 0.38 & 16.90 & 1.14 & 20.42 & 1.90 \\
\hline & & Weekend & 0.01 & 0.59 & 13.13 & 1.01 & 20.11 & 1.43 \\
\hline & & Extended $(24 / 7)$ & 4.90 & 0.64 & 13.14 & 1.29 & 20.00 & 1.52 \\
\hline & \multirow{3}{*}{$\begin{array}{l}12 \text { inches with } \\
6 \text { inches } A C B\end{array}$} & Nighttime & 4.76 & 0.41 & 13.04 & 1.17 & 20.00 & 1.89 \\
\hline & & Weekend & 4.79 & 0.53 & 13.05 & 1.30 & 19.99 & 1.41 \\
\hline & & Extended $(24 / 7)$ & 4.74 & 0.70 & 13.05 & 1.47 & 20.02 & 1.72 \\
\hline \multirow{3}{*}{$\mathbf{A C P}$} & \multirow{3}{*}{$\begin{array}{l}6 \text { inches } \\
(3 \times 2 \text { lift })\end{array}$} & Nighttime & 4.76 & 0.40 & 13.04 & 1.20 & 19.99 & 2.00 \\
\hline & & Weekend & 4.64 & 0.40 & 9.89 & 1.20 & 10.12 & 1.99 \\
\hline & & Extended $(24 / 7)$ & 4.72 & 0.32 & 10.38 & 1.12 & 0.00 & 1.78 \\
\hline \multirow{3}{*}{ МАСО } & \multirow{3}{*}{6 inches } & Nighttime & 4.74 & 1.97 & 13.00 & 5.92 & 19.95 & 9.87 \\
\hline & & Weekend & 4.75 & 2.31 & 12.57 & 6.92 & 17.59 & 11.54 \\
\hline & & Extended $(24 / 7)$ & 4.79 & 2.29 & 12.99 & 6.57 & 17.93 & 11.29 \\
\hline
\end{tabular}

\section{REGRESSION ANALYSIS}

A well-known trade-off effect exists between construction cost and schedule. As Figure 2 shows, there is a normal point beyond the tradeoff between cost and schedule. For example, to shorten the duration of a project by as much as $\Delta \mathrm{T}$ (from $\mathrm{t}_{0}$ to $\mathrm{t}_{1}$ ), a contractor would need to make an additional cost commitment of $\Delta \mathrm{C}$ (from $\mathrm{c}_{0}$ to $\mathrm{c}_{1}$ ). The additional cost increase for shortening construction time involves a direct cost increase covering the use of (1) extra crews (regular plus overtime) and equipment, (2) faster-setting materials, and (3) adoption of methods to expedite delivery of construction materials.

Meanwhile, a delay in the project schedule from the normal point also increases the project cost due largely to increased indirect costs, such as office overhead, overtime payments, running rental equipment longer than originally contracted, etc. (Plummer et al. 1993). 


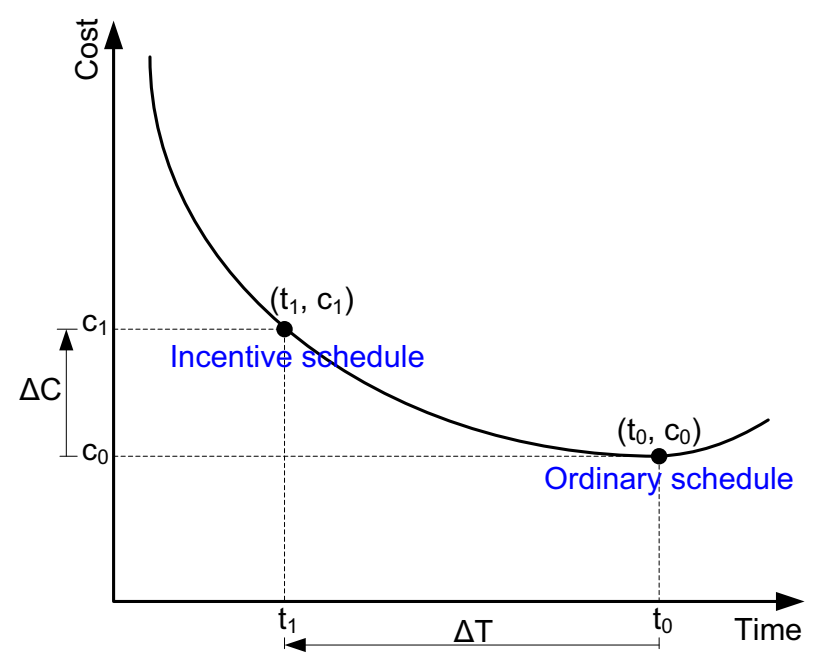

Figure 2: Theoretical time-cost tradeoff curve (adapted from Shr and Chen 2003)

Figure 3, which draws on the regression data in Table 2, confirms that contractors' cost growth as a function of reduced construction times can be projected using the following quadratic equation, which shows a strong tradeoff relationship between schedule and cost.

$$
\text { Cost }=\beta_{0}+\beta_{1}(\text { Time })+\beta_{2}(\text { Time })^{2}
$$

A R-squared value of 0.627 showing a very strong fit indicates that schedule compression begets an increase in project cost.

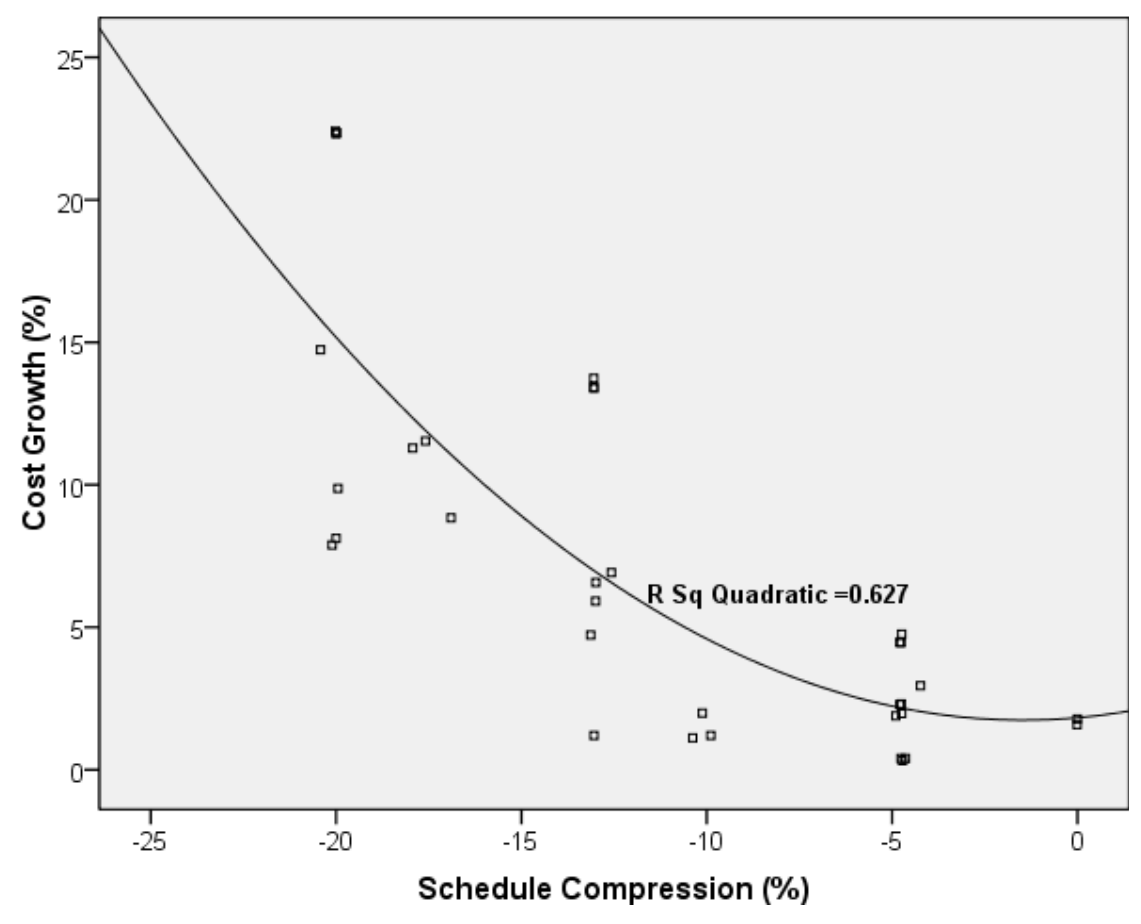

Figure 3: Contractor's time-cost tradeoff curve 


\section{Choi, Kwak and $Y u$}

Table 3 shows that the quadratic equation of contractors' cost growth rate is adequate (F-ratio $=$ 26.005 , significant at .001 level). Since all three coefficients are significant, the following regression equation for determining the lower bound of incentives is generated.

$$
\text { Cost }=1.828+.114(\text { time })+.039(\text { time })^{2}
$$

Table 3: Summary of Regression Analysis Results.

\begin{tabular}{|c|c|c|c|c|}
\hline Model & Coefficient & Std. Error & Beta & t-value \\
\hline Intercept & 1.828 & 2.207 & & $.828^{* *}$ \\
\hline Time & .114 & .469 & .115 & $.244^{*}$ \\
\hline Time-Time & .039 & .020 & .903 & $1.917^{* *}$ \\
\hline \multicolumn{5}{|c|}{$\mathbf{R}^{2}: 0.627$ F ratio: $26.005^{* * *}$} \\
\hline
\end{tabular}

- The F-ratio of 26.005 is significant at level .001 , which suggests that the regression equation is adequate.

- The R-squared value of 0.627 indicates a strong reasonable fit between time and cost.

\section{EQUATION DERIVATION}

By performing a regression analysis, the coefficients $\beta_{0}, \beta_{1}$, and $\beta_{2}$ were determined. From Figure 2 , it is seen that contractors would require committing extra costs by $\Delta \mathrm{C}$ (i.e., $\mathrm{c}_{0}-\mathrm{c}_{1}$ ) to shorten the duration by $\Delta \mathrm{T}$ (from $\mathrm{t}_{0}$ to $\mathrm{t}_{1}$ ). From Equation (3), a time function can be defined as follows:

$$
\mathrm{f}=\beta_{0}+\beta_{1} t+\beta_{2} t^{2}
$$

Since the contractor's additional cost increase is expressed as a function of shortening time by $\Delta \mathrm{T}$, the following relationship can be derived from Figure 2:

$$
\begin{aligned}
\operatorname{CAC}(\Delta \mathrm{C})= & \mathrm{f}\left(\mathrm{t}_{1}\right)-\mathrm{f}\left(\mathrm{t}_{0}\right)=\mathrm{f}\left(\mathrm{t}_{1}\right)-\mathrm{f}\left(\mathrm{t}_{1}+\Delta \mathrm{T}\right) \\
& \text { where, } \mathrm{t}_{0}=\mathrm{t}_{1}+\Delta \mathrm{T}
\end{aligned}
$$

The following equation is derived by combining Equations (5) and (6):

$$
\Delta \mathrm{C} \text { in total }=-\Delta \mathrm{T}\left(2 \beta_{2} \mathrm{t}_{1}+\beta_{1}+\beta_{2} \Delta \mathrm{T}\right)
$$

The negative sign means that cost decreases as time increases. In Equation (7), the symbol $\Delta T$ represents the difference in the number of days necessary to complete the project using conventional and incentive schedules. In other words, $\Delta \mathrm{T}$ reflects the agency goal of schedule reduction. The symbol $\mathrm{t}_{1}$ represents days necessary to complete the project by using an incentive schedule.

To convert the total extra cost increase to a daily basis, Equation (7) needs to be divided by the number of days saved (i.e., $\Delta \mathrm{T}$ ), which cancels out $\Delta \mathrm{T}$. Thus, the contractor's daily additional cost growth rate equals $2 \beta_{2} t_{1}+\beta_{1}+\beta_{2} \Delta T$.

Based on coefficients generated through the regression analysis, the following equations are derived to predict the level of the CAC (Contractor's Additional Cost) to the original contract amount:

$$
\begin{aligned}
\Delta \mathrm{C}= & 0.114+0.078 \mathrm{t}_{1}+0.039 \Delta \mathrm{T} \text { for roadway renewal projects } \\
& \text { where, } \mathrm{t}_{1}=\mathrm{t}_{0}-\Delta \mathrm{T}
\end{aligned}
$$


Using the definition of $t_{1}$, the final equation is derived:

$$
\Delta \mathrm{C}=0.114+0.078 \mathrm{t}_{0}-0.039 \Delta \mathrm{T}
$$

As previously stated, the daily incentive amount should range from an increase in the contractor's daily additional cost to the portion of daily road user cost savings. In symbols,

$$
0.114+0.078 \mathrm{t}_{0}-0.039 \Delta \mathrm{T} \leq \text { Daily } \mathrm{I} / \mathrm{D} \leq \text { Discounted total savings }
$$

\section{PRACTICAL APPLICATION OF MODEL: A CASE STUDY}

The quantitative model of Equation (9) was applied to a long-life I/D highway rehabilitation project, I-15 Devore Project, to test the robustness of the model in estimating the I/D lower bound.

The scope of I-15 Devore project (Caltrans project ID: EA 0A4234), which was selected as an example of the proposed model, was the rehabilitation of a heavily trafficked 2.67-mile stretch of badly damaged concrete truck lanes on I-15 in Devore in Southern California. The goal of applying the model is to determine the realistic I/D lower bound of Equation (10) and to compare this value with the actual I/D amount in order to examine if the agency applied a reasonable I/D amount to the project. The following list includes key information about the rehabilitation project:

- Project size : approximately $\$ 18$ million;

- Lane-miles to be rebuilt: 10.7 lane-miles;

- Construction window: extended weekday closures with around-the-clock operations;

- Lane closure scheme: concurrent double-lane closure with counter-flow traffic;

- Cross-section design: 11.4-in doweled slabs of Type III Portland concrete cement and a 5.9-in asphalt concrete (AR-8000 binder) base;

- AADT (Annual Average Daily Traffic): approximately 100,000 vehicles; and

- Percentage of trucks at the construction work zone: $10 \%$.

Given the project's scope, pavement design, and construction working methods, the agency estimated that the project would require 7.972 -hour weekday closures (24 working days) with a conventional contracting strategy and 6.6 closures (20 working days) in an I/D contracting strategy. The conventional schedule was estimated on the basis of competitive contractors' average resource usage levels, average resource capacity, and average labor productivity. The incentive schedule reflects an accelerated construction schedule that commits additional resources $(15 \%$ more). Labor productivity for the incentive schedule was assumed to be equivalent to that of the conventional schedule. Therefore, four working days (1.3 closures) is the estimated maximum probable number of days that I/D use can eliminate.

According to the agency's calculation, the estimated total saving to road users was estimated to be $\$ 175,151$, given this project's AADT $(100,000)$ and percentage of trucks $(10 \%)$. The expected savings in agency cost by completing the project four days early was estimated to be $\$ 68,400$.

Based on the maximum probable number of days that $\mathrm{I} / \mathrm{D}$ use could eliminate, $\Delta \mathrm{T}$, schedule compression rate, is set to $-0.166\left(16.6 \%\right.$ reduction of $\left.t_{0}\right)$. The contractor's daily additional cost growth rate $(\Delta \mathrm{C})$ is estimated as follows using Equation (9):

$$
0.114+0.078 \mathrm{t}_{0}-0.039 \Delta \mathrm{T}=0.114+0.078(1.000)+0.039(0.166)=0.198 \%=\$ 35,640 / \text { day }
$$

This analysis reveals that the project is an appropriate one for an I/D provision because the estimated lower bound is smaller than the total time value savings in both the daily- and closure-based measurements.

Table 4 shows the lower and upper bounds for determining the most economical I/D amount for the given project. Most agencies would not want to use an amount equivalent to the total time value savings (upper bound) due to budget constraints. It would also be ineffective to set the same amount of total time 


\section{Choi, Kwak and $\mathrm{Yu}$}

value savings as the upper limit even if the agency has an adequate budget for an incentive payment. The model developed in this study provides a reasonable range-based estimate by establishing the I/D lower bound.

Table 4: Lower and Upper Bounds of I/D before Application of a Discount Rate.

\begin{tabular}{l|c|c|c|c}
\hline & $\Delta \mathrm{C}$ & $\begin{array}{c}\text { Savings } \\
\text { to road users }\end{array}$ & $\begin{array}{c}\text { Savings } \\
\text { to the agency }\end{array}$ & Total savings \\
\hline Daily I/D & $\$ 35,640$ & $\$ 175,151$ & $\$ 68,400$ & $\$ 243,551$ \\
\hline Closure I/D & $\$ 106,920$ & $\$ 525,453$ & $\$ 205,200$ & $\$ 730,653$ \\
\hline
\end{tabular}

The maximum incentive amount in this range is within $5 \%$ of the agency's budget for this project. When Caltrans actually implemented this I/D project in 2004, the agency used a daily incentive bonus of $\$ 75,000$, an acceptable (at $70 \%$ discount) amount that can properly motivate the contractor to accomplish an early project completion.

\section{CONCLUSIONS}

This study has introduced a quantitative model for use in establishing the I/D lower bound, which is an estimate for the contractor's additional costs required for expediting the construction in order to meet an accelerated I/D schedule. The proposed model can help transportation agency engineers and decisionmakers make better-informed decisions and allocate more reliable, realistic incentives when they consider the implementation of an incentive/disincentive provision.

The current model presented in this study forms the basis for a future study to develop a decisionsupport computer model for determining the most realistic I/D amounts by integrating three crucial components such as schedule, total time value savings to motorists and to agencies, and contractors' expected additional cost growth. It is recommended that following areas be addressed in the future study to finetune the proposed model's capabilities:

- Expand the model to establish the I/D upper bound as well as the lower bound.

- Expand the model to cover other project types, such as bridges and capacity-added projects. Doing so will enhance the model's analysis capability and give contracting agencies a wider choice of construction strategies.

- Provide point-based estimates of I/D amounts by considering level of service (LOS), which indicate the levels of traffic disruption to motorists.

\section{REFERENCES}

California Department of Transportation (Caltrans). 2008. Labor Surcharge and Equipment Rental Rates. Book, State of California Business, Transportation, and Housing Agency, Division of Construction, Sacramento, California.

Choi, K., E. B. Lee, C. W. Ibbs, and Y. Kim. 2009. Multifaceted public outreach and cost-benefit analysis for its effectiveness validation. Journal of Construction Management and Economics, 27(8):771-782.

Christiansen, D. L. 1987. An analysis of the use of incentive/disincentive contracting provisions for early project completion. Special Report 212, Proceedings of National Conference on Corridor Traffic Management for Major Highway, Transportation Research Board, Washington, D.C.

Herbsman, Z. J., W. T. Chen, and W. C. Epstein. 1995. Time is money: innovative contracting methods in highway construction. Journal of Construction Engineering and Management, ASCE, 121(3):273281. 
Ibarra, C., G. K. Trietsch, and C. L. Dudek. 2002. Strategies used by state DOT's to accelerate highway construction projects. Report, 2002 Mentors Program in Advanced Surface Transportation System, Texas A\&M University, College Station, Texas.

Jaraiedi, M., R. Plummer, and M. S. Aber. 1993. Incentive/disincentive guidelines for highway construction contracts. Journal of Construction Engineering and Management, ASCE, 121(1):112-120.

Lee, E. B., K. Choi, and S. W. Lim. 2008. Streamlined strategies for faster, less traffic-disruptive highway rehabilitation in urban networks." Journal of the Transportation Research Board, Transportation Research Record, No. 2081:38-45, TRB, National Research Council, Washington, D.C.

Lee, E. B. and C. W. Ibbs. 2005. A computer simulation model: construction analysis for highway rehabilitation strategies (CA4PRS). Journal of Construction Engineering and Management, ASCE, 131(4):449-458.

National Academy of Engineering. 2009. Grand Challenges for Engineering. Available via <www.engineeringchallenges.org/cms/8996/9221. aspx> [accessed April 1, 2010].

Plummer, R. W., M. Jaraiedi, and M. S. Aber. 1992. Development of criteria for incentives/disincentives in highway construction contracts. Final Report, Department of Industrial Engineering, West Virginia University, Morgantown, West Virginia.

Shr, J. F., and W. T. Chen. 2003. A method to determine minimum contract bids for incentive highway projects. International Journal of Project Management, 21:601-615.

Sillars, D. N. and J. Riedl. 2007. A framework model for determining incentive/disincentive amounts. Preprints of the Transportation Research Board 86th Annual Meeting, No 06-1817, Transportation Research Board, TRB, National Research Council, Washington, D.C.

US News \& World Report. 2009. Obama: 2.5 Million Jobs By 2011. Available via <www.usnews.com/money/blogs/the-inside-job/2008/11/24/25-millionjobs-by-2011> [accessed March 1, 2010].

Wisconsin Department of Transportation (WisDOT). 2004. Plans \& projects: existing highways. Available via <www.dot.wisconsin.gov/projects/state/sixyear/hwys.html> [accessed February 22, 2010].

\section{AUTHOR BIOGRAPHIES}

KUNHEE CHOI is an assistant professor of construction management at Texas A\&M University. He completed his Ph.D. degree in Civil and Environmental Engineering at the University of California at Berkeley in 2008 and held a position as a researcher at the Institute of Transportation Studies of UC Berkeley for six years. His research has centered around the following three areas: 1) improved project delivery systems; 2) development of an engineered decision-support computer model for complex civil infrastructure systems to aid selection of a solution that would enable agencies to make better-informed decisions; and 3) labor productivity study and streamlined strategies to maximize construction productivity by minimizing project uncertainties. His email address is <kchoi atamu. edu $>$.

YOUNG HOON KWAK (Ph.D., University of California, Berkeley) is a project management faculty member at The George Washington University School of Business in Washington, D.C. Dr. Kwak currently serves as specialty editor (associate editor) for Journal of Construction Engineering and Management (ASCE) and is on the editorial board for International Journal of Project Management (Elsevier), Project Management Journal (Wiley), International Journal of Managing Projects in Business (Emerald), and Journal of Management in Engineering (ASCE). His research interests include strategic issues of project management, project risk management, and engineering, construction, and infrastructure management. He has consulted worldwide and presented and published over 80 scientific papers in project management. For more information, visit his website at $\langle$ http://home.gwu.edu/ kwak $>$. His email address is $<$ kwak@gwu. edu $>$. 
BYUNGGU YU is the Chair of Computer Science and Information Technology at the University of the District of Columbia (UDC). Before joining UDC, he was working at National University and the University of Wyoming. He received his $\mathrm{PhD}$ in Computer Science from Illinois Institute of Technology in the spring of 2000. His activities emphasize systems and informatics. His recent research includes novel techniques for analysis, storage, update, and retrieval of continuously changing information in space-time continuum. Most recently, he has been initiating and conducting new NSF-sponsored sensor-informatics and information assurance projects with his multidisciplinary colleagues. His email address is $<$ byuludc.edu> . 